\title{
Endoscopic transnasal surgery for pure intradural lesions - balance between advantages and disadvantages
}

\author{
Jens Lehmberg
}

Received: 25 August 2010 / Accepted: 26 August 2010 /Published online: 14 September 2010

(C) Springer-Verlag 2010

While reading the table of contents, the readership may ask the following question: Another report on endoscopic transnasal resection of tuberculum sellae meningiomas? Is there really a need for publication? In my personal view, yes, there is!

During the last few years, more and more skull base surgeons have expanded their surgical armamentarium by the endoscopic transnasal approach. The most common pathology treated by this approach is pituitary lesions, but also, the extensions into the anterior, middle and posterior fossas are more and more frequently described. Looking at the number of publications on transnasal endoscopic skull base surgery, one might get the impression that it is a mainstream trend followed by a growing part of skull base surgeons.

Regarding, specifically, tuberculum sellae meningiomas, one might now ask for the rational of the trend towards endoscopic surgery. What are the particular pros and cons of this technique? Furthermore, is this evidence-based practice?

The following advantages and disadvantages are commonly discussed.

The advantages of the transnasal approach:

- No brain retraction due to the route comparable to a meningioma of the convexity

- First detachment of the tumour matrix

- Critical structures like optic nerve or perforators are not obstructing forward view.

J. Lehmberg $(\bowtie)$

Department of Neurosurgery,

Klinikum rechts der Isar Technische Universität München,

Ismaninger Strasse 22,

81675 Munich, Germany

e-mail: jens.lehmberg@1rz.tum.de
The disadvantages of the transnasal approach:

- The endoscope only enables 2D recording.

- Manoeuvrability of the instruments is restricted by the depth of the operative field and the narrowness of the avenue

- intricate dura - and cranioplasty with high rate of cerebrospinal fluid (CSF) fistulas

- limited control of vascular lesions, i.e. carotid artery bleeding.

The evidence upon the resection of a tuberculum sellae meningioma via the transnasal endsocopic route is limited. Only a few series have been published $[1,2,3,4]$ with only a limited number of patients. According to the levels of evidence-based medicine, surgery via the transnasal endoscopic approach is, to date, at level B. To achieve more significant results, publications with an increasing number of treated patients in the level B or a publication in level A, a randomised controlled clinical trial comparing the gold standard, which is the transcranial microscopic surgery versus the transnasal endoscopic technique would be most desirable. In regard to the categories of recommendation, the published series support a recommendation on level C (at least fair scientific evidence suggests that there are benefits provided by the clinical service, but the balance between benefits and risks are too close for making general recommendations. Clinicians need not offer it unless there are individual considerations).

From my personal experience with endoscopic transnasal surgery of tuberculum sellae meningiomas and the perspective from a skull base surgeon, the publication of Ceylan and coworkers might be criticised in crucial points. In three patients, subtotal resection of the tumour was achieved. For frontobasal meningiomas, gross total resection is the goal. Simpson grade I resection can be achieved via a transcranial 
route in almost all cases unless the bone is invaded without damaging carotid or anterior artery, perforators or optic nerve. In particular, when critically reviewing the case displayed in figure 4 (grade II tumour, 59-year-old male), one might ask whether transnasal endoscopic surgery is the appropriate approach. Wang et al. defined the medial margins of the optic nerves as they enter the optic canal as the maximal lateral extension of tuberculum sellae meningiomas eligible by the transsphenoidal route. In my opinion, this tumour should have been resected via a transcranial route, and this is also my opinion with the other two cases with subtotal resection. One can argue that a young patient bearing a small tuberculum sellae meningioma with hyperostosis/bone invasion might be the best candidate for the transnasal route because drilling of this bone might be safer from below than from above. On the other hand, I have to congratulate the authors for their great success in watertight closure of the skull base. No CSF fistula is the best result one can achieve in this step of surgery. Furthermore, this report clearly shows that the risks of the transnasal route are not excessive; no lethal outcome or major vascular damage was described. These two observations might take some wind out of the sceptic sails.

To conclude, there is still a heated debate whether tuberculum sellae meningiomas are eligible for transnasal endoscopic surgery. In my opinion, extradural midline lesions are the best candidates for transnasal endoscopic surgery. For pure intradural lesions, the evidence is sparse. Only the critical review and publication of a large series or a controlled trial will prove the superiority or inferiority of the transnasal or transcranial route.

Conflicts of interest None.

\section{References}

1. de Divitiis E, Esposito F, Cappabianca P, Cavallo LM, de Divitiis O (2008) Tuberculum sellae meningiomas: high route or low route? A series of 51 consecutive cases. Neurosurgery 62(3):556-563

2. Gardner PA, Kassam AB, Thomas A, Snyderman CH, Carrau RL, Mintz AH, Prevedello DM (2008) Endoscopic endonasal resection of anterior cranial base meningiomas. Neurosurgery 63 (1):36-52

3. Laufer I, Anand VK, Schwartz TH (2007) Endoscopic, endonasal extended transsphenoidal, transplanum transtuberculum approach for resection of suprasellar lesions. J Neurosurg 106:400-406

4. Wang Q, Lu XJ, Li B, Ji WY, Chen KL (2009) Extended endoscopic endonasal transsphenoidal removal of tuberculum sellae meningiomas: a preliminary report. J Clin Neurosci 16 (7):889-893 